\title{
The experimental investigation of the ignition petrol mechanism at high temperature metal single particles
}

\author{
Arkadiy V. Zakharevich a and Diana S. Osotova \\ National Research Tomsk Polytechnic University, 634050 Tomsk, Russia
}

\begin{abstract}
The flammable substance by single "hot" metallic particle ignition mechanism are experimentally investigated. On the basis experimental data it is established that the gasoline ignition occurs only with interaction of the mixture of its vapors with air and "hot" particle with the vapors concentrations, which correspond to the evaporating the gasoline conditions at room temperatures. The probability of gasoline vapors mixture with air igniting rapidly is reduced in proportion to their withdrawal from the evaporation surface. Ignition occurs neither in the vapor phase nor on the gasoline surface, even if particle is immersed in it in full or in partly, if the particle temperature is lower than the critical.
\end{abstract}

\section{Introduction}

In the modern methods forecasting fire danger flammable substances commonly used models [1], in which the heat source is a stream or high-temperature gases, or rather a large-scale heat source (volumetric heat source). But sources of ignition occurring in industrial environments are very diverse by the nature as his appearance and by energy. Many fires have occurred due to exposure to capable of burning material (including fluids) particulate metals or their oxides, heated to high temperatures. Single particles sufficiently small size are often sources of fires in industrial and civil objects [2]. Therefore, investigation of the ignition process the liquid fire hazardous substances is practically significant and is also of great interest because the mechanisms of ignition liquids is much harder than condensed materials in the solid state [3-5].

Purpose of work - experimental study of the mechanism ignition petrol "hot" metal particle, which is the source of ignition.

\section{Experimental research methodology}

For the experiment with liquid fire used experimental setup Figure 1, the main element of which is a heating furnace and control and control-measuring block [6]. The object of study - gasoline (petrol) with an octane rating 92 experiments were carried out with a particle source ignition in the form of a disk of fixed diameter $\left(d_{\mathrm{p}}=6 \cdot 10^{-3} \mathrm{~m}\right)$ and height $\left(h_{\mathrm{p}}=5 \cdot 10^{-3} \mathrm{~m}\right)$. The steel particle when falling into a vertical vessel $\left(h=40 \cdot 10^{-3} \mathrm{~m}, d=50 \cdot 10^{-3} \mathrm{~m}\right.$ ) with a liquid fuel (volume $2 \mathrm{ml}$ ) was in the solid

\footnotetext{
${ }^{\text {a }}$ Corresponding author: bet@tpu.ru
}

This is an Open Access article distributed under the terms of the Creative Commons Attribution License 4.0, which permits unrestricted use, distribution, and reproduction in any medium, provided the original work is properly cited. 


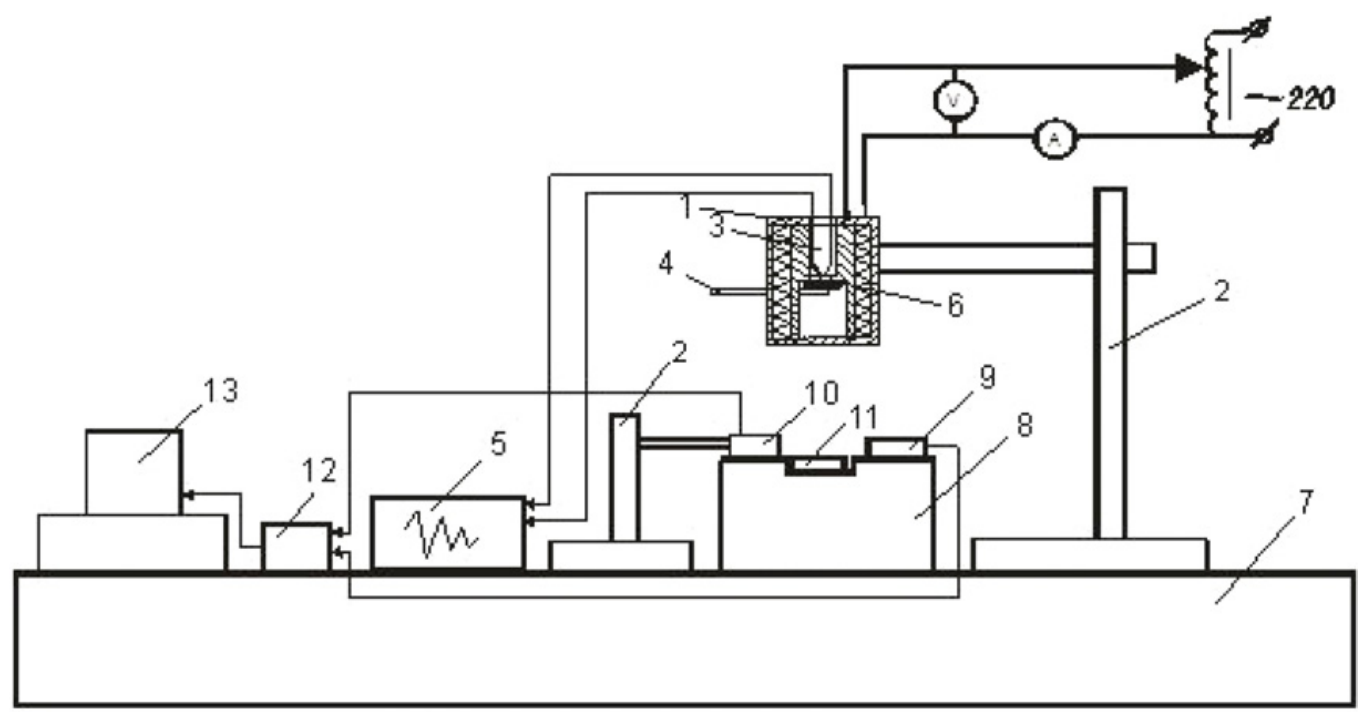

Figure 1. Schematic diagram of the experimental installation: (1) heating device; (2) support; (3) chromel-alumel thermocouple; (4) ceramic rod; (5) temperature control device; (6) metal particle; (7) working surface of the experimental setup; (8) fire-resistant area; (9) radiation receiver and flame recorder; (10) radiation source; (11) glass cylindrical vessel with a film of liquid fuel; (12) analog-to-digital converter; (13) personal computer.

state and is not deformed. Experiments were carried out in a well-reproducible conditions at a constant temperature of the heat source at least 6 times in a row. In all the experiments carried out video of the processes studied. Heating the metal disc to a predetermined temperature was performed in a heating furnace (Fig. 1), providing stable temperature of the working volume $(1400 \mathrm{~K})$ for a prolonged time. Measurement error of the initial temperature of the particles, as measured by the method of [7], did not exceed $1-3 \%$.

To assess the scope of temperature change the particle an ignition source of gasoline in the process of falling to solve the problem of heat conduction for the disc. Considered during the fall of the particles on the surface of the fire hazardous substances. The problem was solved with the boundary conditions of the third kind on the disc surface. Heat transfer coefficient was calculated from the dependences [8], taking into account changes in the velocity of the particle. It is established that during the fall of the temperature of the particle surface with the liquid fuel is reduced by not more than $4 \mathrm{~K}$. This deviation can be neglected in the analysis, as in the experiments was achieved by particle temperature over $1273 \mathrm{~K}$. Accordingly, during the drop from the exit of the heating furnace to the point (not more than $0.2 \mathrm{sec}$ ) change in temperature of the particle surface is not more than $0.4 \%$. Such an error in determining the $T_{\mathrm{p}}$ is acceptable.

To assess the scope of temperature change the particle an ignition source of gasoline in the process of falling to solve the problem of heat conduction for the disc. Considered during the fall of the particles on the surface of the fire hazardous substances. The problem was solved with the boundary conditions of the third kind on the disc surface. Heat transfer coefficient was calculated from the dependences [8], taking into account changes in the velocity of the particle. It is established that during the fall of the temperature of the particle surface with the liquid fuel is reduced by not more than $4 \mathrm{C}$. This deviation can be neglected in the analysis, as in the experiments was achieved by particle temperature over $1273 \mathrm{~K}$. Accordingly, during the drop from the exit of the heating furnace to the point (not more than $0.2 \mathrm{sec}$ ) change in temperature of the particle surface is not more than $0.4 \%$. Such an error in determining the $T_{p}$ is acceptable. 
a)

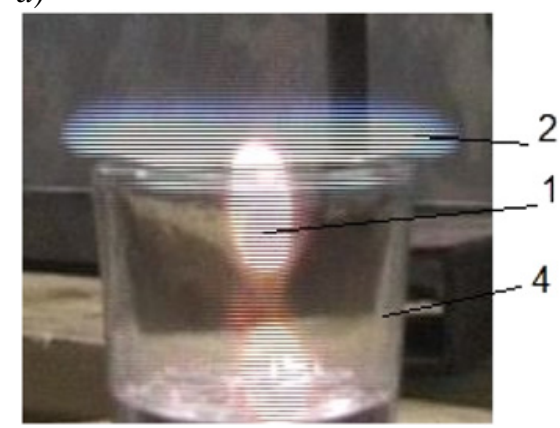

b)

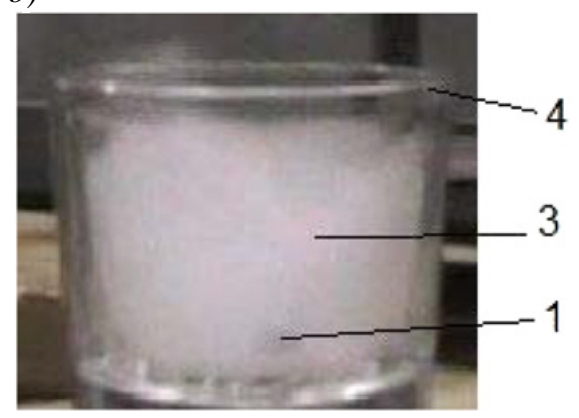

Figure 2. Frames video recordings experiment with inflammation (a) and without ignition (b) gasoline: 1 - hot metal particle; 2 - flame; 3 - gasoline vapors high concentration; 4 - vertical glass jar.

\section{Results of experimental studies}

Experiments have shown that the ignition occurs in the fuel vapor phase before the particle fall on the surface combustible liquid when the temperature of particle more than $1353 \mathrm{~K}$. If $T_{\mathrm{p}}$ is less than this value, the ignition does not occur even if the particle dives in gasoline entirely or partially. Diagrams (Figs. 2a, 2b) illustrate embodiments of ignition and non-incendive. Further increase of $T_{r m p}$ provides unconditional ignition of gasoline in the vapor phase.

This result can be explained as follows. Gasoline is a volatile liquid. Therefore even at room temperature an intensive evaporation of gasoline occurs which is enough for create a critical concentration in the air of gasoline vapor, as shown by experiments. These gasoline vapors during the motion of the evaporation surface are mixed with air. Inflammation occurs when heated to high (more than $1353 \mathrm{~K}$ ) temperature of the particles fall into this combustible mixture.

Is interesting that if temperature is lower than the critical temperature, the ignition of gasoline does not occur even if the particle falls into the layer of the liquid. In this case, a significant part of the energy stored in the particle is spent in intensive evaporation of gasoline. But vaporous products implementing this process have low temperature insufficient to cause ignition. With distance from the surface of the phase transition it is cooled more by the heat exchange with the ambient air. Probability of ignition of the mixture of gasoline vapor and air decreases rapidly as they move away from the evaporation surface. The obtained results allow to conclude that the ignition of gasoline by single heated to a high temperature particles is only possible directly in the layer of gasoline vapor at some distance from the evaporation surface even at room temperature (20-25 degrees). A necessary condition for ignition in this case is the high temperature of the particle.

Should be emphasized that the mechanisms of ignition of diesel fuel [9] and gasoline are significantly different. Ignition of diesel fuel occurs after contact with a "hot" steel particles near the surface of the liquid. Since the thickness of this layer is less than the height of the steel particle, the particle ignites the liquid when it is in liquid. This difference is due to the peculiarities of the phase transition of the two distillate fuels. The rate of evaporation of gasoline is substantially higher, and the heat of phase transition is lower in comparison with the diesel fuel.

On the basis of research results, we can conclude that the exposed surfaces of the gasoline at normal room temperatures are effective suppliers of fuel for ignition reactions. Sources of ignition may be not only "hot" particles, but also other sources of high temperature (incandescent wire, high-temperature elements heaters, open fires, etc.).

The results of the experiments also allow us to conclude about the high fire danger exposed surfaces of gasoline even in situations when heated to temperatures above $1353 \mathrm{~K}$ particles pass at some distance 
from the evaporation surface of the combustible liquid. Most dangerous in these conditions are works on welding and cutting metals. In these works the particles are formed at a temperature higher than usually the melting temperature of steel (e.g. 1773-1873 K).

The obtained results are the basis for the specification and development of mathematical models of ignition of flammable liquids and liquid fuels $[10,11]$ by local energy sources.

\section{Conclusions}

The first carried out experimental study of the mechanism ignition petrol single heated to a high temperature particles allowed to identify the main features of this process. It is found that the ignition petrol occurs only by reacting a mixture of vapor and air and a "hot" the particle at concentrations of vapors that are appropriate fuel vapors at room temperature. If the particle temperature below the critical value, ignition does not occur in the vapor phase or on the surface of the petrol even if the particle is immersed in it completely or partially.

\section{References}

[1] J. Warnatz, U. Maas, R.W. Dibble, Combustion. The physical and chemical aspects, simulation experiments, the formation of contaminants (FIZMATLIT, Moscow, 2003)

[2] N.I. Akinin, N.N. Bulhov, V.A. Gerish, Pozharovzryvobezopasnost. 19, 53 (2010)

[3] D.A. Frank-Kamenetsky, Diffusion and heat transfer in chemical kinetics (Plenum, New York, 1969)

[4] G.V. Kuznetsov, G. Ya. Mamontov, G.V. Taratushkina, Khimicheskaya Fizika.23, 67 (2004)

[5] V.L. Strakhov, A.N. Garashchenko, G.V. Kuznetsov, V.P. Rudzinskii, Combustion, Explosion and Shock Waves. 37, 212 (2001)

[6] A.V. Zakharevich, V.T. Kuznetsov, G.V. Kuznetsov, V.I. Maksimov, Combust. Explos., Shock Waves. 44, 543 (2008)

[7] Y.V. Polezhaev, F.B. Jurevich, Thermal protection (Energy, Moscow, 1976)

[8] V.P. Isachenko, Heat transfer (Energoizdat, Moscow, 1981)

[9] A.V. Zakharevich, N.S. Belkov, EPS Web of Conferences. 75, 1 (2014)

[10] O.V. Vysokomornaya, G.V. Kuznetsov, P.A. Strizhak, Russ. J. Phys. Chem. B 5, 668 (2011)

[11] G.V. Kuznetsov, P.A. Strizhak, J. Eng. Thermophys. 18, 162 (2009) 